\title{
Feminist killjoys e reflexões (in)felizes sobre obstinação e felicidade
}

Willful subjects.

AHMED, Sara.
Durham and London: Duke University
Press, 2014.

Quando consentimos sobre a necessidade de sermos felizes ao que, de fato, se consente? O que se defende junto ao direito à felicidade? Qual é o peso da obstinação numa sociedade cujas regras para o "bem viver" parecem tão claras? Onde estão as pessoas que não "sentam à mesa da felicidade" na história de nossa cultura?' Estas são questões do interesse de Sara Ahmed nos livros the promise of happiness (2010) e Willful subjects (2014) quando se aproxima da felicidade e da obstinação ${ }^{2}$ e de como são tratadas na cultura ocidental. Os temas são problematizados, a partir de questões de natureza diversa, trazidos pela vida social e política contemporâneas e, principalmente, pelo lugar central que a felicidade recebe nas representações sobre ética e moralidade que perpassa este momento histórico. Mais do que refletir sobre "o que é felicidade", a autora busca responder "o que a felicidade faz" e quais outros conceitos ela engendra quando, enfim, se participa ou não de sua busca.

As duas obras partilham um problema comum, que é inicialmente abordado em The promise of Happiness (AHMED, 2010) e que é ampliado e tratado mais detidamente em Willful Subjects (AHMED, 2014), com relação ao tema das feminist killjoys ${ }^{3}$ e de como a experiência de ser feminista - que vem atrelada ao próprio "feminismo/ser feminista" como um traço identitário possível no último quarto de século - gera uma representação negativa (de, supostamente, desejada infelicidade) em determinadas esferas sociais. É impossível para este momento relatar com propriedade todas as contribuições dos dois livros e, por esse motivo, gostaria de centrar atenções para as ideias como killjoy, queer unhappiness e de obstinação, na medida em que oferecem proposições teóricas e epistemológicas importantes para o campo de estudos de gênero, e respostas interessantes para problemas feministas.

Há no momento contemporâneo um esforço, que vem tanto do campo políticoinstitucional quanto do campo acadêmico e de movimentos sociais, em torno da busca da felicidade e, mais especificamente, da felicidade como uma forma de descrever um tipo específico de comportamento e de compromissos subjetivos. Nesse quadro do qual fala a autora ser feliz é mais do que um desejo subjetivo próprio, mas também um fator importante em culturas terapêuticas; livros e CDs de autoajuda; produções de alguns segmentos do campo dos saberes psi; leituras ocidentais de tradições tais como o budismo, entre outras práticas. A felicidade aparece como o resultado de posicionamentos, relações sociais, de associar-se com projetos já consolidados de felicidade; está baseada com o querer envolverse com quem também quer a felicidade e muito importante na argumentação da autora - com objetos aos quais historicamente foram atribuídos poderes de felicidade, tais como a família, pessoas e hábitos específicos. Seria possível, em face de um projeto já bastante consolidado, falar de uma indústria do bemestar e de uma ciência da felicidade, que se desenham tendo a felicidade como um de seus principais bastiões, envolvendo a criação de 
revistas acadêmicas interdisciplinares sobre $\circ$ tema e índices de desenvolvimento políticoeconômico que incluiriam a felicidade como um de seus indicadores 4 .

Para Ahmed (2010; 2014), portanto, a felicidade não estaria somente em sensações interiores ao sujeito, mas também no desejo de objetos e contextos que materializam sua busca. Assim, podemos "ser feitos felizes" por meio de determinados objetos porque eles encapsulam um conjunto de atributos e relações. Ao utilizá-los ou buscá-los, estaríamos também buscando a felicidade. Essa é uma premissa importante da autora, pois apresenta o fato de que a felicidade não está à parte ou autônoma de relações (AHMED, 2010, p. 22) e que o que se constrói na experiência social do sujeito é a fórmula segundo a qual "felicidade" é o que se encontra se se persegue determinados objetos e relações. A felicidade, assim, é um resultado do reconhecimento desses objetos felizes e, mutuamente, da intencionalidade dos sujeitos. Nesse conjunto, o próprio desejo por determinados objetos também se torna um importante elemento da busca pela felicidade, pois "o bom sujeito" não vai experimentar o prazer que vem dos objetos errados, mas experienciar uma certa quantidade de prazer somente nos objetos certos (AHMED, 2010, p. 37). A felicidade é uma promessa que direciona para determinados tipos de objetos em nossa sociedade, dos quais seriam exemplos a família, o casamento, os estilos de vida etc. Um exemplo de como são tratados teoricamente pela autora pode ser encontrado na família: sua transformação num "objeto de felicidade" carregaria simultaneamente condições que a tornam um aspecto legítimo da autorrealização pessoal, a saber, a forma como atrela relações (afetos às pessoas) e outros objetos de felicidade (a mesa de jantar, os jogos familiares) num mesmo conjunto de alinhamentos que, uma vez alcançados, geram felicidade para o eu e para outros que estão ou estarão envolvidos (AHMED, 2010, p. 45-46).

Um ponto aparece, assim, como crucial na história que Ahmed quer tratar: o que acontece com os sujeitos que não perseguiram esses objetos de felicidade, que "estragaram o prazer" da família ou não viveram o prazer nos objetos certos? Tais sujeitos, e a autora busca apresentar um pequeno conjunto deles, estariam no que ela chama de arquivos infelizes (unhappy archives) da história da felicidade e eles seriam precisamente (a) as mulheres feministas e seus hábitos "estraga-prazeres" (feminist killjoy); (b) os "queers infelizes", isto é, sujeitos cujas histórias simplesmente não poderiam inadvertidamente possuir finais felizes; e (c) os "migrantes melancólicos", os sujeitos que vivem em outros contextos culturais e cujas trajetórias sempre são supostamente infelizes. Os arquivos da infelicidade são os elementos que constituem a história que Ahmed quer reconstruir e ela $\circ$ faz exatamente ao suspender a ideia de que felicidade é algo bom e instiga o/a leitor/a a olhar para o que esses espaços infelizes da história da felicidade causam ao panorama mais geral de nossas crenças sobre a relação entre coisas boas/felicidade. Duas conclusões já se anunciam a partir disso: a) a associação de determinados sentimentos com o rótulo de felicidade são construções históricas e, ao compulsar os arquivos infelizes, a autora mostra como aparecem ao longo do tempo; b) é possível viver uma vida que não se pauta na felicidade normativa (aquela felicidade prescritiva, cujos objetos de desejo já são pressupostos) e, ainda assim, não se reconhecer como diminuídos/as pelo discurso mais amplo de felicidade.

Após a publicação do clássico The Feminine Mystique - de Betty Friedan (1971 [1965]) - uma série de críticas sobre a ideia da felicidade da dona de casa passa a habitar e capitanear o movimento feminista nos Estados Unidos. A crítica de Friedan sugere que, sob a constante reiteração de que a dona de casa norte-americana se encontra muito feliz em seus afazeres, se encontra, na verdade, a obliteração de uma construção generificada de papéis sociais a respeito do trabalho. Como a teoria feminista viria a construir posteriormente, sobretudo nas discussões de bell hooks ${ }^{5}$, a situação descrita por Betty Friedan na verdade era somente parcial e não dizia respeito a todas as mulheres norte-americanas. Seguindo as trilhas desse argumento, que provém da teoria feminista negra, Ahmed dirá que, da mesma forma que a fantasia da dona de casa feliz submete o trabalho doméstico à lógica da felicidade, a fantasia da dona de casa liberada de seus afazeres submete, sob esta lógica da felicidade, o trabalho de outras tantas mulheres que, como argumentou hooks, serão chamadas a assumirem aquele lugar. $O$ ponto central nesta inflexão teórica é o de que as críticas das autoras promovem a conscientização de que no tocante à imagem da "dona de casa feliz" impera não somente uma não distribuição igualitária da "felicidade" como tal, mas uma má distribuição de uma promessa ou de uma ideia de um sentimento específico de felicidade.

Contemporaneamente, a ideia da "dona de casa feliz" estaria, não obstante, retornando (a partir da mesma virada midiática e literária em torno da busca da felicidade) e o argumento 
feminista da busca da "libertação da mulher" (como aparece em Friedan) revelando-se, neste novo contexto, como a grande infelicidade contemporânea da mulher. Blogs e diários virtuais passam a oferecer manuais (incluindo as mais diversas receitas culinárias) para que a mulher aprenda a ser feliz no ambiente doméstico, (re)descobrindo, portanto, a real felicidade em tais afazeres. Nesse contexto, no qual o feminismo é tomado como o libertador da mulher e, ao mesmo tempo, responsabilizado também pela infelicidade das mulheres, é que emerge a categoria do feminist killjoy, pois, afinal, estariam as feministas constantemente estragando a busca por felicidade de outras pessoas com seus processos de conscientização geradores de infelicidade. Um segundo momento descrito pela autora é o da infelicidade de personagens queer nas histórias usuais sobre relacionamentos nãoheterossexuais: não se poderia registrar a felicidade de casais homossexuais sem o risco de que pudesse afetar a compreensão das pessoas sobre o destino de quem "escolhe" como objeto de felicidade um conjunto de relações que não está qualificado a oferecer felicidade.

Ressonâncias importantes da discussão da autora nesse primeiro momento - em The promise of Happiness (2010) - podem ser encontradas na obra que o segue, Willful subjects (AHMED, 2014): se a obstinação das pessoas, sua persistência em torno de determinados temas, a tendência em assumir posições e objetos de felicidade errados é o que leva alguns sujeitos à condição de infelicidade; então, o problema está precisamente nas vontades que são expressadas no veículo subjetivo da obstinação/ teimosia ${ }^{6}$. Ora, se a felicidade é um projeto, entre outros elementos que a autora destaca, do desejo (will) pessoal, então a busca da felicidade e os problemas que levanta se interconectam nas trajetórias de sujeitos que tiveram em suas biografias rompimentos relacionados à sua suposta teimosia/obstinação (willfulness). Infelicidade e obstinação são, assim, igualmente objetos políticos e rastros a serem perseguidos a fim de produzirem um reconhecimento da vida social de determinados sujeitos.

Essas duas publicações são um relato da felicidade como uma grande "virada" (happiness turn) contemporânea que domina a cena midiática, a literatura, o campo da saúde, e outras esferas, como um tema referencial para a experiência da "boa vida" ou do "viver bem" e de como, enfim, a busca da felicidade está imbricada num processo mais amplo, no qual determinados sujeitos são oprimidos. Ahmed oferece uma história alternativa para a felicidade, não somente ao oferecer uma leitura das tradições filosóficas que já se debruçaram sobre o conceito, mas inserindo aqueles sujeitos que são exatamente banidos da "história oficial", as pessoas que causam problemas, "joy killers" (AHMED, 2010, p. 17). No segundo caso (AHMED, 2014), trata-se de pensar a ideia da obstinação ou da teimosia (willfulness) como uma maneira de perseguir ou rastrear relações nas quais a quebra de regras torna o sujeito obstinado/ teimoso como alguém que se interpõe no decurso de normas socialmente estabelecidas na realização de papéis e de tarefas prédeterminadas às pessoas e, por fim, na alegada felicidade de outras pessoas. Na história da "obstinação", a mera persistência é um ato de desobediência e, na tradição cultural que compartilhamos, desobedecer equivale a "preferir a infelicidade", coadunar com o desejo de morte, passivamente morrer.

Em todos os casos descritos a partir dos trabalhos de Ahmed, o que se encontra é uma defesa de políticas da identidade que passem pela "negatividade", pelo killjoy, pela obstinação: pelo reconhecimento da necessidade de estragar os prazeres que, pelos diversos processos de conscientização feministas, as mulheres já foram levadas a desconstruir; pelo reconhecimento de que o queer não precisa ter um final feliz, pelo menos não "normativamente feliz". É possível encontrar solidariedade entre aqueles sujeitos que partilham a experiência do killjoy. Narrar a história dessas mulheres como unicamente de infelicidade obscurece o que tal "infelicidade" fez pela história dessas pessoas. Narrar a infelicidade, afirma Ahmed para o caso das relações queer (AHMED, 2010, p. 107), pode ser também afirmativo, positivo, e apontar para novas possibilidades sociais, além de revelar não somente o que a felicidade faz, mas o que a experiência da "nãofelicidade" nos moldes normativos ocidentais permite que as pessoas façam. Enfim, que se possa falar de uma infelicidade em moldes queer (queer unhappiness) ao invés de "queers infelizes" desde a perspectiva da cultura dominante. Com essa proposta - que é a rigor política e também de natureza epistemológica - Ahmed aponta para a necessidade de construirmos perspectivas que reconheçam que determinadas pessoas simplesmente não poderão ter os futuros ou cumprir as promessas que determinados projetos de felicidade oferecem: como narrar a vida de tais pessoas? Como reconhecer suas histórias de obstinação como histórias onde igualmente se é possivel encontrar algo? 


\section{Notas}

' O texto toma como fio condutor o conceito de feminist killjoy que aparece em obra anterior de Ahmed (2010) e confere significado expressivo ao tema da obstinação, abordado em Ahmed (2014). A motivação para este diálogo entre a obra mais recente e a obra anterior se deve à relevância epistemológica e política do conceito como um eixo condutor importante da proposição de Ahmed de (re)construir uma história tomando como referência os sujeitos que estão às margens dos projetos consolidados de felicidade.

${ }^{2}$ Termo de difícil tradução no livro de Ahmed (2014) é a expressão willful. Ela pode simultaneamente designar a "teimosia" de uma criança ou adolescente que não faz o que lhe é mandado fazer, ou que escolhe caminhos que são tomados como inseguros ou anormais (willful children); como pode também designar a obstinação na busca e adoção de perspectivas éticas e morais contrastantes com normas vigentes (como quem busca questionar a heteronormatividade). Optei por sugerir nesta resenha uma leitura de willful como obstinada/o, a fim de manter a ideia de que há sujeitos que obstinadamente fogem da "regra" da felicidade e seguem caminhos infelizes, da perspectiva da sociedade em que vivemos. Esta tradução obscurece, no entanto, o jogo linguístico envolvendo willfulness como inadequação do will, do desejar ou do desejo propriamente, isto é, de sujeitos que "desejam errado" ou "desejam muito", na perspectiva apresentada por Ahmed. Estou ainda totalmente consciente de que a ideia de obstinação/teimosia pode sugerir erroneamente que os sujeitos optam/agem deliberadamente contra a regra geral. A complexidade das vidas queer e da(s) identidade(s) LGBTs face aos "projetos históricos de felicidade", bem como a extensão social e política da heteronormatividade densificam a ideia de opção ou agência atribuída a estes sujeitos. Deve-se lembrar que um sujeito obstinado não é somente alguém que deseja sê-lo, mas alguém que é julgado como tal pela sociedade envolvente.
${ }^{3}$ Algo em torno de "estraga-prazeres feminista". As pessoas que supostamente buscam sempre estar "no caminho" dos outros para a busca da felicidade. A expressão em inglês será eventualmente mantida.

${ }^{4}$ Ver como exemplos o Gross National Happiness (em países de língua portuguesa traduzido como Felicidade Interna Bruta, FIB) ou Journal of Happiness Studies, publicado pela Editora Springer.

${ }^{5}$ Ver, entre outros, Feminist Theory: from margin to centers (2000 [1984]).

${ }^{6}$ Novamente aqui temos um importante elemento da tradução que merece ser destacado. Na língua inglesa o termo will descreve, de acordo com a construção envolvida, vontade, desejo (desejar), querer. Significativamente, o radical will aparece na construção do substantivo willful e também willfulness que representam "condições anormais" do querer pessoal. Especialmente em Wilful Subjects (2014) a autora trabalha com as ambiguidades linguísticas que advêm da escrita sobre estes termos: "If to be willful is to become a problem, then willfulness can be understood as a problem of will" (AHMED, 2014, p. 3).

\section{Referênclas}

AHMED, Sara. The promise of happiness. Durham and London: Duke University Press, 2010.

Wilful subjects. Durham and London: Duke University Press, 2014.

FRIEDAN, Betty. Mística feminina. Petrópolis: Vozes, 1971.

hooks, bell. Feminist Theory: From Margin to Center. NY Boston: South End Press, 2000 [1984].

[Recebida em: 25/03/2016 e aceita para publicação em: 25/04/2016]

Fernando José Ciello Universidade Federal de Santa Catarina, Florianópolis, Santa Catarina, Brasil

1022 Estudos Feministas, Florianópolis, 24(3): 000, setembro-dezembro/2016 